\title{
Tratamento de sementes de Avena sativa l. com zinco: qualidade fisiológica e desempenho inicial de plantas
}

\author{
Seed treatment of Avena sativa l. with zinc: \\ physiological quality and performance of initial plans
}

\author{
Sandro de Oliveira ${ }^{1 *}$; Lizandro Ciciliano Tavares ${ }^{1}$; Elisa Souza Lemes ${ }^{1}$; \\ André Pich Brunes ${ }^{1}$; Igor Leitzk Dias²; Géri Eduardo Meneghello ${ }^{3}$
}

\begin{abstract}
Resumo
A produção e a qualidade fisiológica das sementes estão diretamente associadas a uma boa disponibilidade de nutrientes na lavoura. A produção de sementes em áreas com deficiência de zinco, pode gerar sementes com baixo conteúdo e concentração deste micronutriente, logo as plântulas são menos vigorosas podendo refletir em baixo rendimento. Neste contexto, o presente trabalho tem como objetivo avaliar a influência do recobrimento de sementes de aveia branca com zinco na qualidade fisiológica das sementes e no crescimento inicial de plantas. $\mathrm{O}$ delineamento experimental adotado foi inteiramente casualizado, em um esquema fatorial 2 X 5, sendo dois produtos (Teprosyn ${ }^{\mathrm{TM}} \mathrm{Zn}$ e Quimifol seed $78^{\circledR}$ ) e cinco doses $(0$, $100,200,300$ e $400 \mathrm{~mL}$ do produto $100 \mathrm{~kg}^{-1}$ de semente) com quatro repetições. A qualidade fisiológica das sementes tratadas foi avaliada pelos testes de primeira contagem de germinação, germinação e envelhecimento acelerado. Para o crescimento inicial das plantas foram avaliadas as variáveis altura de planta, área foliar e matéria seca de plantas, sendo que com os dados de área foliar e matérias seca das plantas calculou-se as taxas de crescimento da cultura (TCC), taxa de crescimento relativo (TCR) e taxa assimilatória líquida (TAL), sendo as mesmas mensuradas em três períodos (10, 20 e $30 \mathrm{DAE})$. Os produtos Teprosyn ${ }^{\mathrm{TM}} \mathrm{Zn}$ e Quimifol seed $78^{\circledR}$ podem ser usados no tratamento de sementes até as doses de 100 e $200 \mathrm{~mL} 100 \mathrm{~kg}^{-1}$ de sementes respectivamente, sem prejudicar a qualidade fisiológica das sementes. O produto Teprosyn ${ }^{\mathrm{TM}} \mathrm{Zn}$ com $17 \mathrm{~g} \mathrm{~L}^{-1}$ de nitrogênio e $600 \mathrm{~g} \mathrm{~L}^{-1}$ de zinco, a partir da dose de $200 \mathrm{~mL} 100 \mathrm{~kg}^{-1}$ de sementes, 30 dias após a emergência, apresenta menor crescimento de planta e área foliar, comparativamente a dose de máxima eficiência técnica.
\end{abstract}

Palavras-chave: Aveia branca, vigor, germinação, crescimento de plantas

\begin{abstract}
The production and physiological seed quality are directly associated with a good availability of nutrients in the crop. Seed production in areas with zinc deficiency, can generate seeds with low content and concentration of this micronutrient, the logo may be less vigorous seedlings, which may reflect in low yield. In this context, this work aims to evaluate the influence of seed coating with zinc in oat seed physiological quality and initial growth of plants. The experimental design was completely randomized in a factorial 2 X 5, two products (Teprosyn ${ }^{\mathrm{TM}} \mathrm{Zn}$ and seed Quimifol $\left.78{ }^{\circledR}\right)$ and five doses $(0,100,200$, 300 and 400 of the product $100 \mathrm{ml} \mathrm{kg-1}$ seed) with four replications. The treated seed physiological quality was evaluated by testing first germination, germination and accelerated aging. For the initial
\end{abstract}

\footnotetext{
${ }^{1}$ Discentes do Curso de Doutorado em Ciência e Tecnologia de Sementes. Universidade Federal de Pelotas, UFPel, Pelotas, RS. E-mail: sandrofaem@yahoo.com.br; lizandro_cicilianotavares@yahoo.com.br; lemes.elisa@yahoo.com.br; beldar_brunes@msn.com

${ }^{2}$ Discente do Curso de Graduação em Agronomia da Faculdade de Agronomia Eliseu Maciel, UFPel, Pelotas, RS. E-mail: igorleitzk@hotmail.com

${ }^{3}$ Dr. em Ciência e Tecnologia em Sementes, UFPel, Pelotas, RS. E-mail: gmeneghello@gmail.com

* Autor para correspondência
} 
plant growth variables plant height, leaf area and dry weight of plants were evaluated, and with the data of leaf area and dry matter of the plants was calculated growth rates of culture (TCC), rate relative growth (RGR) and net assimilation rate (NAR) and measured in the same three periods $(10,20$ and 30 DAE). The Teprosyn ${ }^{\mathrm{TM}} \mathrm{Zn}$ and seed Quimifol $78 \AA$ products can be used as a seed treatment to doses

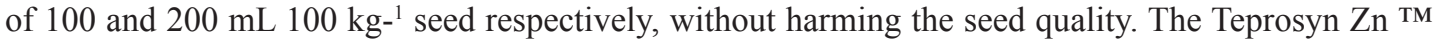
product with $17 \mathrm{~g} \mathrm{~L}^{-1}$ of nitrogen and $600 \mathrm{~g}$ of zinc $\mathrm{L}^{-1}$, from the dose of $200 \mathrm{~mL}$ for $100 \mathrm{~kg}^{-1}$ seeds, 30 days after emergence, plant shows reduced growth and leaf area compared to maximum dose of technical efficiency.

Key words: Oat, vigor, germination, plant growth

\section{Introdução}

A aveia-branca é um cereal utilizado tanto na alimentação humana quanto animal, pois apresenta um balanceamento de aminoácidos, vitaminas, minerais e carboidratos de alta qualidade (VELLOSO; FEDERIZI, 2000). Possui importância para a exploração agrícola no período de estação fria do ano, principalmente sendo utilizada como cultura benéfica no sistema de rotação de culturas (TUNES et al., 2008).

A utilização de sementes de qualidade é fundamental para se obter uma boa produção, visto que, este insumo é ponto de partida para obter emergência e estande de plantas uniforme, requisitos básicos de uma lavoura com elevado potencial de produtividade. A produção e a qualidade fisiológica das sementes são diretamente dependente da disponibilidade de nutrientes na lavoura, por afetar a formação do embrião e dos órgãos de reserva, assim como a composição química e, consequentemente, o metabolismo e o vigor (CARVALHO; NAKAGAWA, 2000).

Os nutrientes apresentam papel relevante durante as fases de formação, desenvolvimento e maturação das sementes, principalmente na constituição das membranas celulares e no acúmulo de lipídios, carboidratos e proteínas (SÁ, 1994). Plantas cultivadas em condição de deficiência de zinco $(\mathrm{Zn})$, geralmente, produzem sementes com baixo conteúdo e concentração desse nutriente, logo as plântulas são menos vigorosas podendo refletir em baixo rendimento na colheita. $\mathrm{O} \mathrm{Zn}$ é considerado como um elemento acelerador do crescimento da radícula em estudos envolvendo sementes de arroz
(OHSE et al., 2000) e trigo (PRADO et al., 2007), tendo ainda, importante papel durante a germinação das sementes e no crescimento inicial das plântulas, já que uma grande quantidade de $\mathrm{Zn}$ presente nas sementes pode exercer efeitos protetores contra patógenos do solo e contra infestação radicular de nematóides, além de contribuir para tolerância a estresses abióticos (CAKMAK, 2005). A maioria dos estudos realizados no Brasil consideram $1 \mu \mathrm{g} /$ ml (1 ppm) como nível crítico de zinco no solo (extrator Mehlch 1, DTPA a pH 7.3 e $\mathrm{HCl}$ 0,1 N), sendo assim muitos solos brasileiros possuem teores de zinco inadequados para o cultivo agrícola, seja pelo material de origem ou pelo uso intensivo do solo sem a devida reposição (RIBEIRO; SANTOS, 1996). As doses de zinco requeridas pelas culturas são pequenas (FURLANI, 1996), existindo assim dificuldade em distribuir uniformemente os adubos na aplicação via solo (RIBEIRO; SANTOS, 1996), restando como alternativa a aplicação foliar, no entanto, as pulverizações apresentam como desvantagem a baixa mobilidade do zinco no floema (LONGNECKER; ROBSON, 1993).

Estudos mostram que a aplicação de $\mathrm{Zn}$ via tratamento de sementes é viável para o provimento deste para a cultura do milho, atendendo especialmente a fase inicial de crescimento da planta (RIBEIRO; SANTOS, 1996). A aplicação de zinco via semente pode ser uma forma adequada e promissora, em virtude das pequenas quantidades exigidas pelas plantas, melhor uniformidade de distribuição, menor custo de aplicação e também pela garantia da nutrição no estádio inicial de crescimento onde o sistema radicular é pouco 
desenvolvido, afetando a aquisição do nutriente no solo (BONNECARRÉRE et al., 2004).

Diante desse contexto, o presente trabalho tem como objetivo avaliar a influência do recobrimento de sementes de aveia branca com zinco na qualidade fisiológica das sementes e no crescimento inicial de plantas.

\section{Material e Métodos}

O experimento foi realizado na Faculdade de Agronomia Eliseu Maciel da Universidade Federal de Pelotas (UFPel). Foram utilizadas sementes de aveia branca, cultivar Barbarasul.

Os tratamentos em esquema fatorial $2 \mathrm{X} 5$, consistiram nas combinações de dois produtos à base de zinco (Teprosyn ${ }^{\mathrm{TM}} \mathrm{Zn}$ e Quimifol seed $78^{\circledR}$ ) com diferentes doses dos produtos $(0,100,200,300 \mathrm{e}$ $400 \mathrm{~mL}$ do produto $100 \mathrm{~kg}^{-1}$ de semente), totalizando 10 tratamentos, com quatro repetições. Os produtos apresentavam as seguintes características: Produto Teprosyn $^{\text {TM }} \mathrm{Zn}$ com densidade $1,67 \mathrm{~kg} \mathrm{~L}^{-1}$, possuindo em sua constituição $17 \mathrm{~g} \mathrm{~L}^{-1}$ de nitrogênio e $600 \mathrm{~g} \mathrm{~L}^{-1}$ de $\mathrm{Zn}$ e o produto Quimifol seed $78^{\circledR}$, que apresenta densidade de $1,75 \mathrm{~kg} \mathrm{~L}^{-1}$, possuindo $780 \mathrm{~g} \mathrm{~L}^{-1}$ de $\mathrm{Zn}$, tendo como garantia 45\% de Zn.

Após o tratamento das sementes com zinco, as mesmas também foram recobertas com polímero $\left(\right.$ Sepiret ${ }^{\mathbb{R}}$ ) na dose de $250 \mathrm{~mL} 100 \mathrm{~kg}^{-1}$ de sementes. A proporção do volume de calda foi mantida em 800 $\mathrm{mL} 100 \mathrm{~kg}^{-1}$ de sementes para todos os tratamentos adicionando-se água. O tratamento foi realizado em sacos de polietileno, seguindo procedimento descrito por Nunes (2005), em que foram depositadas no fundo do saco as fontes em suas determinadas doses, juntamente com o polímero e com a água para completar o volume de calda. Posteriormente, no fundo dos sacos foram colocados $100 \mathrm{~g}$ de sementes, as quais foram agitadas por 3 minutos, após isso, foram postas para secas a temperatura ambiente durante 24 horas.
A qualidade das sementes tratadas foi avaliada logo após o tratamento, quanto a:

Germinação (G): conduzida com 200 sementes, com quatro repetições de 50 sementes por tratamento, utilizando como substrato rolos de papel germitest previamente umedecidos com água destilada na proporção de 2,5 vezes a massa do papel seco e mantido em germinador à temperatura de $20{ }^{\circ} \mathrm{C}$. As avaliações foram efetuadas dez dias após a semeadura (BRASIL, 2009) e os resultados expressos em porcentagem.

Primeira Contagem de Germinação (PCG): realizada conjuntamente com o teste de germinação, consistiu no registro da porcentagem de plântulas normais efetuado no quinto dia após a semeadura, sendo os resultados expressos em porcentagem.

Envelhecimento Acelerado (EA): foi utilizado caixa gerbox com tela metálica fixada na posição mediana, sendo adicionados $40 \mathrm{~mL}$ de água destilada ao fundo de cada caixa gerbox, e sobre a tela foi distribuída uma camada uniforme de sementes de cada tratamento a fim de cobrir a superfície da tela, constituindo uma única camada. Em seguida, as caixas contendo as sementes foram tampadas e acondicionadas em incubadora do tipo $\mathrm{BOD}$, a $41^{\circ} \mathrm{C}$, onde permaneceram por 72 horas (MARCOS FILHO, 1999). Após este período, as sementes foram submetidas ao teste de germinação, conforme descrito anteriormente. A avaliação foi realizada aos cinco dias após a semeadura, sendo os resultados expressos em porcentagem.

Para a realização das análises de crescimento foi realizada a semeadura de seis sementes por repetição, em vasos plásticos com capacidade de 15 litros, preenchidos com solo coletado do horizonte A1 de um Planossolo Háplico Eutrófico solódico, (STRECK et al., 2008), pertencente à unidade de mapeamento de Pelotas-RS. As adubações foram realizadas de acordo com CFQS RS/SC (Comissão de Fertilidade e Química do Solo - RS/SC, 2004), utilizando-se apenas nitrogênio, fósforo e potássio, 
os quais foram incorporados ao solo no momento da semeadura. Após a emergência foi realizado desbaste, permanecendo apenas três plantas por vaso.

Para a avaliação do crescimento inicial da cultura analisaram-se as seguintes variáveis: Altura de planta (AP), área foliar (AF) e massa seca da parte aérea (MSPA). Para tanto realizou-se a coleta de uma planta por repetição de cada tratamento, cortada no sentindo horário ao nível do solo, aos 10, 20, e 30 dias após a emergência (DAE). A AF foi realizada, utilizando-se determinador fotoelétrico (Area Meter, modelo Li-cor LI-3100) que fornece leitura direta $\mathrm{em} \mathrm{cm}^{2}$. Para determinação da AP, realizouse a medição com auxílio de régua milimetrada, sendo os resultados expressos em centímetros. A MSPA foi realizada, pelo método de estufa a $60^{\circ} \mathrm{C}$, no qual as plântulas foram mantidas por período de 72 horas em estufa elétrica com circulação de ar e após pesadas em balança analítica (NAKAGAWA, 1999). Com os resultados da área foliar e da massa seca da parte aérea das plantas foram determinadas: taxa de crescimento da cultura, TCC (mg pl ${ }^{-1}$ dia $^{-}$ $\left.{ }^{1}\right)$; taxa de crescimento relativo, TCR ( $\mathrm{mg} \mathrm{g}^{-1} \mathrm{dia}^{-}$ $\left.{ }^{1}\right)$; taxa de assimilação líquida, TAL ( $\left.\mathrm{mg} \mathrm{cm}^{-2} \mathrm{dia}^{-1}\right)$. Essas determinações basearam-se na metodologia descrita em Gardner, Pearce e Mitchell (1985), em que: $\mathrm{TCC}=\left(\mathrm{MS}_{2}-\mathrm{MS}_{1}\right) /\left(\mathrm{T}_{2}-\mathrm{T}_{1}\right) ; \mathrm{TCR}=\left(\ln \mathrm{MS}_{2}-\right.$ $\left.\ln \mathrm{MS}_{1}\right) /\left(\mathrm{T}_{2}-\mathrm{T}_{1}\right) ; \mathrm{TAL}=\left(\mathrm{MS}_{2}-\mathrm{MS}_{1}\right) /\left(\mathrm{T}_{2}-\mathrm{T}_{1}\right) *(\ln$ $\left.\mathrm{AF}_{2}-\ln \mathrm{AF}_{1}\right) /\left(\mathrm{AF}_{2}-\mathrm{AF}_{1}\right)$; onde: MS: massa seca, T: tempo, AF: área foliar, ln: logaritmo neperiano.

Os dados obtidos foram submetidos à análise de variância e, na presença de interação significativa, procederam-se os desdobramentos necessários. Os dados em percentagem foram transformados para arcsen raiz $(\mathrm{x} / 100)$, sendo apresentados os dados originais. As médias do fator qualitativo foram comparadas pelo teste de Tukey a 5\% de probabilidade, já as médias do fator quantitativo foram analisadas por regressão polinomial. $\mathrm{Na}$ execução das análises estatísticas foi utilizado o sistema de análise estatística Winstat versão 1.0 (MACHADO; CONCEIÇÃO, 2003).

\section{Resultados e Discussão}

Não foi constatada interação entre os dois fatores avaliados. Para o teste da primeira contagem de germinação o produto Quimifol seed $78^{\circledR}$ apresenta-se superior ao produto Teprosyn ${ }^{\mathrm{TM}} \mathrm{Zn}$, independentemente das doses estudadas. Para a germinação e envelhecimento acelerado, o tratamento das sementes com as duas fontes de $\mathrm{Zn}$ não diferiram estatisticamente (tabela 1). Da mesma forma o recobrimento de sementes de arroz irrigado com zinco não promoveu acréscimos na germinação e no vigor das sementes (OHSE et al., 2000). No entanto, em trabalho com sementes de sorgo tratadas com zinco $(0,3,57,7,14,14,28$ e 28,56 g de zinco por $\mathrm{kg}$ de sementes) tendo como fonte sulfato de zinco heptahidratado, foi constatado redução da percentagem de germinação com o aumento das doses (YAGI et al., 2006).

Aos 10 DAE não foi constatada diferença para as variáveis analisadas, exceto para MS, em que o produto Quimifol seed $78^{\circledR}$ foi superior (tabela 2). $\mathrm{Na}$ avaliação aos $20 \mathrm{DAE}$ o produto Teprosyn ${ }^{\mathrm{TM}} \mathrm{Zn}$ foi superior ao produto Quimifol seed $78^{\circledR}$ para a AF. Aos 30 DAE a AP e AF das plantas oriundas de sementes tratadas com $\mathrm{Zn}$ sofreram influência significativa, tanto dos produtos bem como das doses. Infere-se que as sementes tratadas com $\mathrm{Zn}$ sofram influência positiva no crescimento inicial das plantas de aveia, no entanto doses mais elevadas podem ser prejudiciais, conforme observado com o produto Teprosyn ${ }^{\mathrm{TM}} \mathrm{Zn}$ na dose de $400 \mathrm{~mL}$ por 100 $\mathrm{Kg}$ de sementes que afetou a AP e AF. O zinco pode promover maior crescimento e desenvolvimento das plantas, alongando o entre nó do caule com reflexos na altura, podendo assim justificar sua utilização (MALAVOLTA; BOARETTO; PAULINO, 1991). Ohse et al. (2012), tratando sementes de melancia com diferentes doses de zinco, verificaram que o zinco reduziu o vigor das sementes, quando avaliado pelo teste de comprimento e massa fresca e seca de plântulas. Por outro lado, efeitos significativos do Zn em milho, na altura de planta, foram observados com variações de respostas dependendo da 
cultivar, podendo esse efeito ser positivo em baixas concentrações e em alguns casos negativo em altas concentrações do nutriente (FURLANI et al., 2005). Já a aplicação de zinco em diferentes formas na cultura do trigo, não afetaram as variáveis de crescimento das plantas, embora tenha incrementado a concentração do micronutriente no solo e na planta (ORIOLI JUNIOR et al., 2008). A MS aos 20 e 30 DAE não apresentou diferença significativa para os produtos estudados. Semelhantemente, a aplicação de doses de zinco em sementes de arroz (1,0; 2,0; 4,0 e 8,0 $\mathrm{g} \mathrm{Zn} \mathrm{kg}^{-1}$ sementes), tendo como fontes oxido e sulfato de zinco, não apresentou efeito significativo para a matéria seca quando comparado com a testemunha (ROZANE et al., 2008).

Os dados referentes à taxa de crescimento da cultura (TCC), taxa de crescimento relativo (TCR) e taxa de assimilação líquida (TAL), referente a três períodos de avaliação (1 a 10, 11 a 21 e 21 a 30 DAE) estão apresentados na Tabela 3. Para a
TCC observa-se que o tratamento das sementes de aveia com $\mathrm{Zn}$ foi superior para o produto Quimifol seed $78^{\circledR}$, no primeiro período de avaliação (1 a 10 DAE), não ocorrendo diferença para os demais períodos. A TCR é a medida mais apropriada para a avaliação do crescimento vegetal, uma vez que é uma estimativa da eficiência da planta em acumular matéria seca (BRIGGS; KIDD; WEST, 1920). A TCR não apresentou diferença entre as fontes de Zn para os períodos de avaliação. No entanto, para a TAL (taxa de assimilação líquida) os resultados mostram que ocorreu interação entre os fatores doses e fontes, no último período de avaliação. $\mathrm{O}$ recobrimento das sementes com as fontes de $\mathrm{Zn}$ foi superior para o produto Quimifol seed $78^{\circledR}$ até a dose de $300 \mathrm{~mL}$ por $100 \mathrm{Kg}$ de sementes, sendo que na dose de $400 \mathrm{~mL}$ por $100 \mathrm{Kg}$ de sementes não foi observado diferença significativa entres os produtos estudados.

Tabela 1. Primeira contagem de germinação (PCG), germinação (G), envelhecimento acelerado (EA), de sementes de aveia recobertas com fontes e doses de zinco.

\begin{tabular}{|c|c|c|c|c|c|c|}
\hline \multirow{3}{*}{ Dose* } & \multicolumn{6}{|c|}{ Produto } \\
\hline & $\mathbf{A}$ & B & $\mathbf{A}$ & B & $\mathbf{A}$ & B \\
\hline & \multicolumn{2}{|c|}{ PCG $(\%)$} & \multicolumn{2}{|c|}{ G (\%) } & \multicolumn{2}{|c|}{ EA $(\%)$} \\
\hline 0 & 79 & 82 & 88 & 87 & 81 & 81 \\
\hline 100 & 80 & 82 & 92 & 88 & 83 & 83 \\
\hline 200 & 75 & 83 & 88 & 90 & 84 & 83 \\
\hline 300 & 74 & 81 & 84 & 89 & 85 & 85 \\
\hline 400 & 68 & 77 & 76 & 85 & 83 & 83 \\
\hline Média & $75 b^{* *}$ & $81 \mathrm{a}$ & $86 \mathrm{a}$ & $88 \mathrm{a}$ & $84 \mathrm{a}$ & $83 \mathrm{a}$ \\
\hline C V (\%) & \multicolumn{2}{|c|}{7,3} & \multicolumn{2}{|c|}{6,5} & \multicolumn{2}{|c|}{4,8} \\
\hline
\end{tabular}

*mL do produto100 kg de Sementes ${ }^{-1}$, **Médias seguidas pela mesma letra minúscula na linha, em cada variável resposta, não diferem pelo teste de Tukey a 5\% de probabilidade. Produto A (Teprosyn ${ }^{\mathrm{TM}} \mathrm{Zn}$ ): 17 e $600 \mathrm{~g} \mathrm{~L}^{-1}$ nitrogênio e Zn, respectivamente, Produto B (Quimifol seed $78^{\circledR}$ ): $780 \mathrm{~g} \mathrm{~L}^{-1}$ de zinco.

Fonte: Elaboração dos autores. 
Tabela 2. Altura de planta (AP), área foliar (AF) e massa seca (MS), aos 10, 20 e 30 dias após a emergência (DAE) de plantas oriundas de sementes de aveia recobertas com fontes e doses de zinco.

\begin{tabular}{|c|c|c|c|c|c|c|}
\hline \multirow{3}{*}{ Dose* } & \multicolumn{6}{|c|}{ Período } \\
\hline & \multicolumn{2}{|c|}{$\mathrm{AP}(\mathrm{cm})$} & \multicolumn{2}{|c|}{$\mathrm{AF}\left(\mathrm{cm}^{2} \mathrm{pl}^{-1}\right)$} & \multicolumn{2}{|c|}{$\mathrm{MS}\left(\mathrm{mg} \mathrm{pl}^{-1}\right)$} \\
\hline & A & $\mathrm{B}$ & A & $\mathrm{B}$ & A & $\mathrm{B}$ \\
\hline & \multicolumn{6}{|c|}{ Avaliação 10 dias após a emergência } \\
\hline 0 & 13,3 & 13,4 & 6,4 & 6,6 & 28,43 & 31,03 \\
\hline 100 & 14,3 & 13,0 & 7,4 & 5,9 & 28,35 & 31,60 \\
\hline 200 & 14,8 & 13,4 & 7,0 & 6,4 & 28,75 & 31,88 \\
\hline 300 & 13,5 & 13,7 & 6,2 & 7,2 & 29,08 & 32,40 \\
\hline 400 & 13,8 & 14,1 & 7,2 & 7,0 & 29,30 & 33,03 \\
\hline \multirow[t]{2}{*}{ Média } & $13,9 \mathrm{a}^{* *}$ & $13,5 \mathrm{a}$ & $6,8 \mathrm{a}$ & $6,6 \mathrm{a}$ & $28,78 \mathrm{~b}$ & $31,73 \mathrm{a}$ \\
\hline & \multicolumn{6}{|c|}{ Avaliação 20 dias após a emergência } \\
\hline 0 & 23,0 & 22,1 & 17,2 & 13,2 & 75,90 & 75,98 \\
\hline 100 & 23,6 & 18,0 & 19,1 & 13,3 & 76,03 & 76,13 \\
\hline 200 & 23,0 & 22,8 & 18,8 & 16,3 & 77,20 & 77,30 \\
\hline 300 & 21,4 & 22,8 & 19,2 & 15,1 & 79,00 & 81,35 \\
\hline 400 & 21,6 & 21,5 & 14,6 & 14,6 & 79,25 & 82,68 \\
\hline Média & $22,5 \mathrm{a}$ & $21,4 \mathrm{a}$ & $17,8 \mathrm{a}$ & $14,5 \mathrm{~b}$ & $77,48 \mathrm{a}$ & $77,69 \mathrm{a}$ \\
\hline C.V. $(\%)$ & \multicolumn{2}{|c|}{11,9} & \multicolumn{2}{|c|}{11,4} & \multicolumn{2}{|c|}{11,1} \\
\hline & \multicolumn{6}{|c|}{ Avaliação 30 dias após a emergência } \\
\hline 0 & $37,2 \mathrm{a}$ & $40,6 \mathrm{a}$ & $54,9 \mathrm{a}$ & 58,6 a & 249,45 & 249,13 \\
\hline 100 & $41,4 \mathrm{a}$ & $35,4 \mathrm{~b}$ & $62,6 \mathrm{a}$ & $44,9 \mathrm{~b}$ & 252,00 & 250,65 \\
\hline 200 & $41,4 \mathrm{a}$ & $35,9 \mathrm{~b}$ & $61,3 \mathrm{a}$ & $46,6 \mathrm{~b}$ & 260,75 & 262,55 \\
\hline 300 & $37,7 \mathrm{a}$ & $37,8 \mathrm{a}$ & $59,4 \mathrm{a}$ & $44,6 \mathrm{~b}$ & 267,68 & 267,43 \\
\hline 400 & $33,8 \mathrm{~b}$ & $38,7 \mathrm{a}$ & $46,8 \mathrm{~b}$ & 56,9 a & 273,08 & 274,00 \\
\hline Média & 38,3 & 37,6 & 57,0 & 49,3 & $260,59 \mathrm{a}$ & $257,44 \mathrm{a}$ \\
\hline C.V. (\%) & \multicolumn{2}{|c|}{5,5} & \multicolumn{2}{|c|}{8,8} & \multicolumn{2}{|c|}{6,7} \\
\hline
\end{tabular}

*mL do produto100 $\mathrm{kg}$ de Sementes ${ }^{-1}$, **Médias seguidas pela mesma letra minúscula na linha, em cada variável resposta, não diferem pelo teste de Tukey a 5\% de probabilidade. Produto A (Teprosyn ${ }^{\mathrm{TM}} \mathrm{Zn}$ ): 17 e $600 \mathrm{~g} \mathrm{~L}^{-1}$ nitrogênio e Zn, respectivamente, Produto B (Quimifol seed 78 ${ }^{\circledR}$ ): $780 \mathrm{~g} \mathrm{~L}^{-1}$ de zinco.

Fonte: Elaboração dos autores. 
Tabela 3. Taxa de crescimento da cultura (TCC), taxa de crescimento relativo (TCR) e taxa de assimilação liquida (TAL), em 3 períodos (1 a 10, 11 a 20 e 21 a 30 DAE) de plantas oriundas de sementes de aveia recobertas com fontes e doses de zinco.

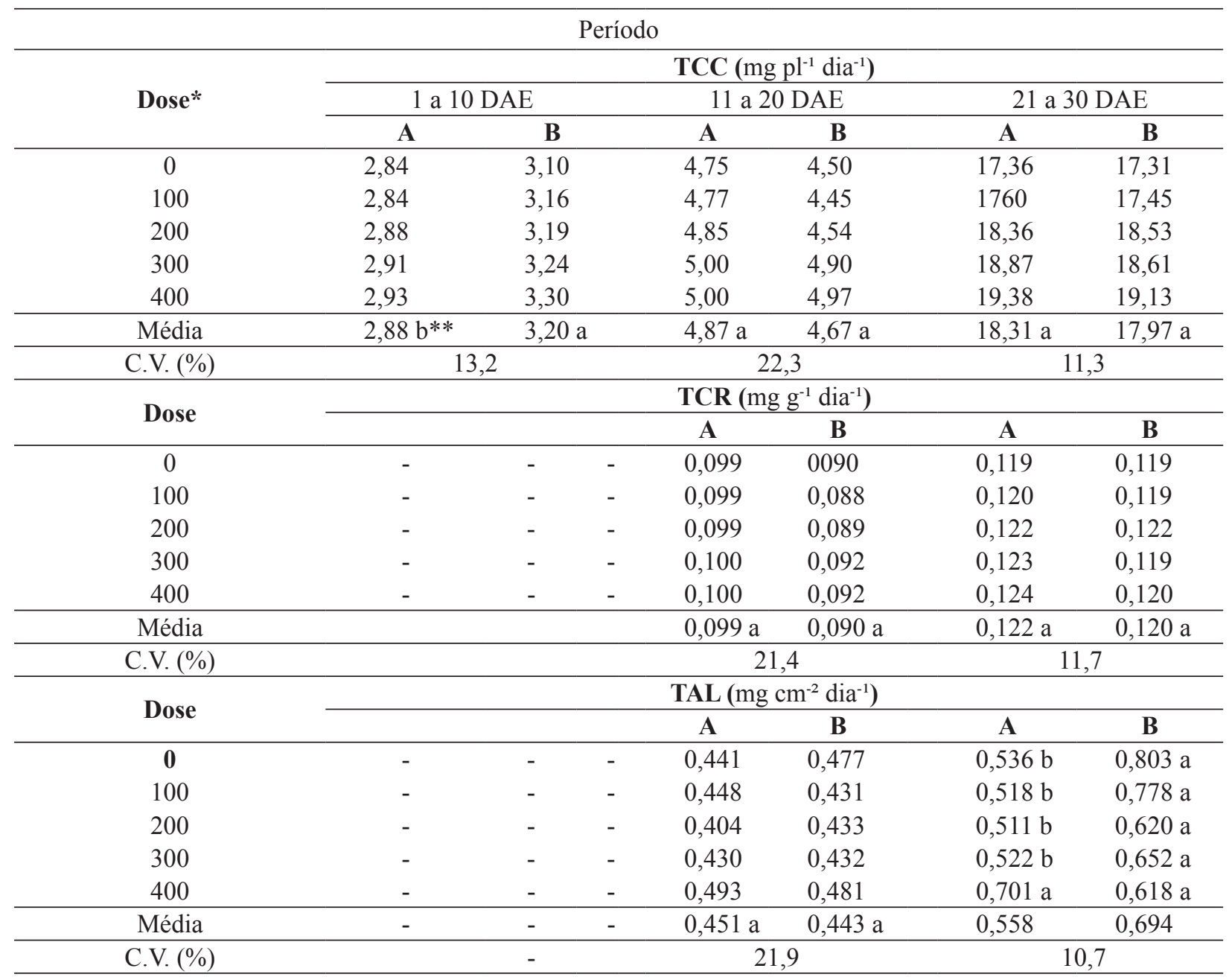

*mL do produto100 $\mathrm{kg}$ de Sementes ${ }^{-1}$, **Médias seguidas pela mesma letra minúscula na linha, em cada variável resposta, não diferem pelo teste de Tukey a 5\% de probabilidade. Produto A (Teprosyn ${ }^{\mathrm{TM}} \mathrm{Zn}$ ): 17 e $600 \mathrm{~g} \mathrm{~L}^{-1}$ nitrogênio e Zn, respectivamente, Produto B (Quimifol seed 78 ${ }^{\circledR}$ ): $780 \mathrm{~g} \mathrm{~L}^{-1}$ de zinco.

Fonte: Elaboração dos autores.

A TAL, por sua vez, reflete a dimensão do sistema assimilador que está envolvida na produção de matéria seca, ou seja, é uma estimativa da taxa de fotossíntese líquida, sendo dependente de fatores ambientais, principalmente da radiação solar (HUXLEY, 1967). Segundo Ribeiro e Santos (1996), uma planta bem nutrida em zinco apresenta maior desenvolvimento inicial, principalmente em condições adversas e em substratos carentes do nutriente. Desta forma, uma planta com maior desenvolvimento inicial pode apresentar maior acréscimo em suas taxas de crescimento.

Os dados apresentaram comportamento quadrático, tanto para a primeira contagem de germinação, quanto para a germinação (Figura 1). O ponto de máxima para a primeira contagem de germinação é obtido com uma dose de 77,5 mL 100 $\mathrm{kg}$ sementes- ${ }^{-1}$ independente do produto a base de Zn aplicado às sementes e a partir dessa dose ocorre reduções da germinação. Para germinação o ponto 
de máxima é obtido com uma dose de $170 \mathrm{~mL} 100$ $\mathrm{kg}$ sementes $^{-1}$. A partir desse ponto, houve efeito deletério das doses de $\mathrm{Zn}$ sobre a germinação. O Zn é requerido em pequenas quantidades, apresentando uma estreita faixa entre o efeito benéfico e a toxicidade (MALAVOLTA, 2006), explicando a redução na germinação a partir da dose de máxima eficiência. Tais resultados concordam com os encontrado por Yagi et al. (2006) que trabalhando com sementes de sorgo tratadas com cinco doses $\mathrm{Zn}$, observou pequeno acréscimo com seguida redução nos percentuais de germinação. No entanto Fungueto et al. (2010) não verificaram diferenças significativa na germinação de sementes de arroz tratadas com fontes de $\mathrm{Zn}$, fungicida e polímeros.

Figura 1. Primeira Contagem de Germinação (PCG) e Germinação (G), de sementes de aveia recobertas com fontes e doses de zinco.

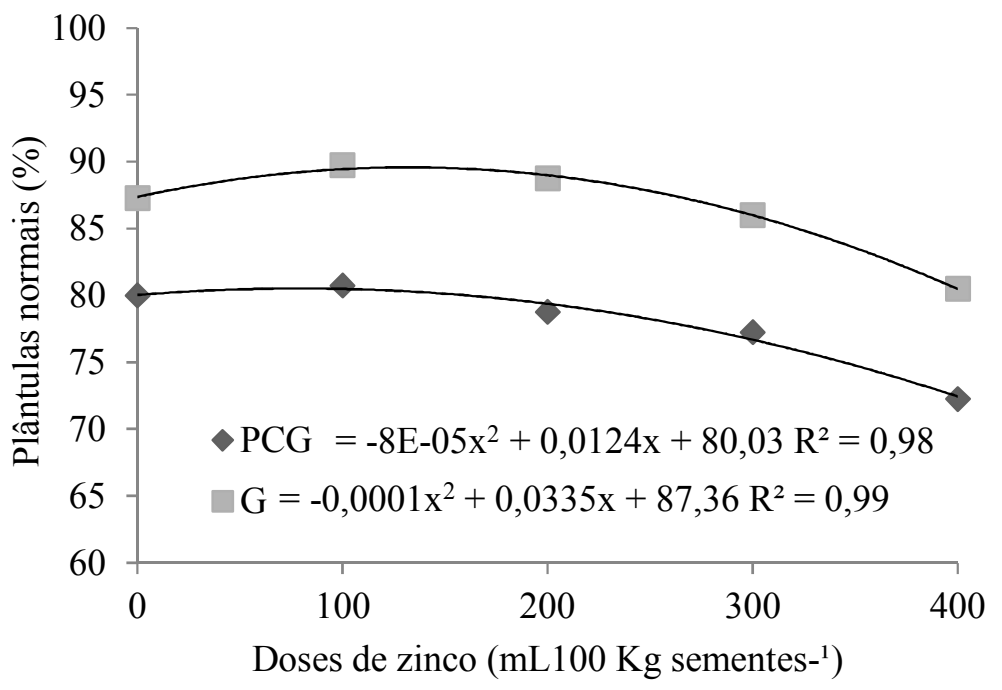

Fonte: Elaboração dos autores.

A máxima área foliar $\left(17,58 \mathrm{~cm}^{2}\right.$ planta $\left.^{-1}\right)$ foi obtida com a dose de $210 \mathrm{~mL} 100 \mathrm{~kg}$ sementes $^{-1}$ (Figura 2). A partir desse ponto houve reduções da área foliar das plântulas de aveia branca no período avaliado. Na Figura 3 verifica-se que para a altura de planta, área foliar e massa seca aos 30 DAE, os produtos apresentaram respostas diferentes com o aumento das doses testadas. Para AP (Figura 3A) o produto Quimifol seed $78^{\circledR}$ em doses mais baixas foi prejudicial ao desenvolvimento da planta e com as doses mais elevadas os valores ficaram próximos ao valor inicial. $\mathrm{O}$ produto Teprosyn ${ }^{\mathrm{TM}} \mathrm{Zn}$ até o ponto de máxima, o qual foi na dose de $235 \mathrm{~mL} 100$ $\mathrm{kg}$ sementes $^{-1}$ foi benéfico para AP, sendo que nas doses acima desse ponto apresentou efeito negativo. A AF aos 30 dias após a emergência (Figura 3B) obteve comportamento semelhante ao da AP, sendo o produto Teprosyn ${ }^{\mathrm{TM}} \mathrm{Zn}$ benéfico para essa até o ponto de máxima, a qual foi na dose de 163 $\mathrm{mL} 100 \mathrm{~kg}$ sementes $^{-1}$, com o aumento da dose a partir deste ponto observou um efeito negativo. A MS apresentada na Figura 3C enquadrou-se em um comportamento linear crescente, onde para cada aumento de $1 \mathrm{ml}$ por $100 \mathrm{~kg}$ de sementes a massa seca aumenta $0,067 \mathrm{mg} \mathrm{pl}^{-1}$. Resultados semelhantes foram encontrados por Santos e Ribeiro (1994), que trabalhando com milho, concluíram que os tratamentos com Zn aumentaram significativamente a produção de MSPA. Por outro lado Fageria (2000), trabalhando com aplicação de Zn via solo observou incremento da massa seca de arroz em $36 \%$ e $14 \%$ em milho, em relação à testemunha. 
Figura 2. Área Foliar (AF) aos 20 dias após a emergência de plantas oriundas de sementes recobertas com fontes e doses de zinco.

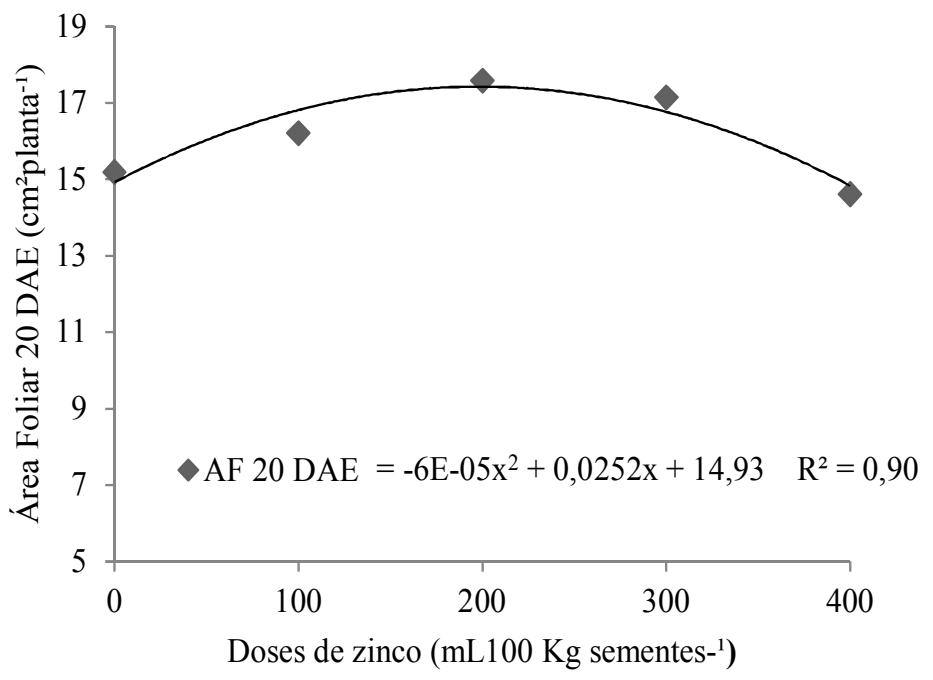

Fonte: Elaboração dos autores.

Figura 3. Altura de Planta (AP), Área Foliar (AF) e Massa Seca (MS), aos 30 dias após a emergência de plantas oriundas de sementes recobertas com fontes e doses de zinco.
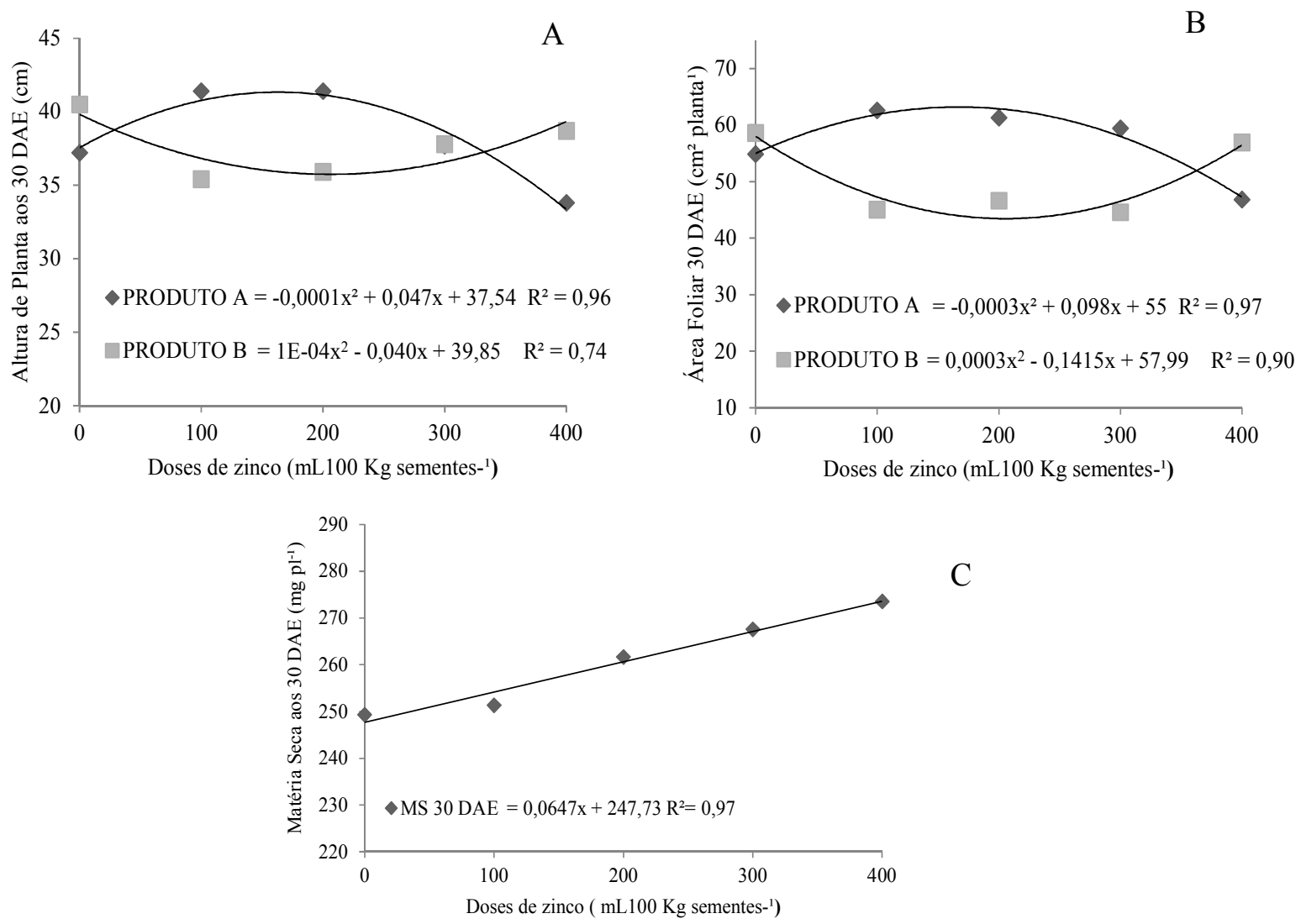

Fonte: Elaboração dos autores. 
A Figura 4 refere-se à TAL de 21 a 30 dias após a emergência de plantas oriundas de sementes tratadas com duas fontes $\mathrm{Zn}$. Observa-se que o produto Teprosyn $^{\mathrm{TM}} \mathrm{Zn}$ apresentou um comportamento quadrático, sendo que até o ponto de mínima, que é o ponto de $133 \mathrm{~mL} 100 \mathrm{~kg}$ sementes $^{-1}$, apresenta um decréscimo na TAL, a partir deste ponto o acréscimo de doses proporcionou um incremento na variável analisada. Já o produto Quimifol seed $78^{\circledR}$ apresentou um comportamento linear, o qual proporcionou redução da taxa de assimilação líquida com o aumento das doses estudadas.

Figura 4. Taxa de Assimilação Liquida (TAL), de 21 a 30 dias após a emergência de plantas oriundas de sementes recobertas com fontes e doses de zinco.

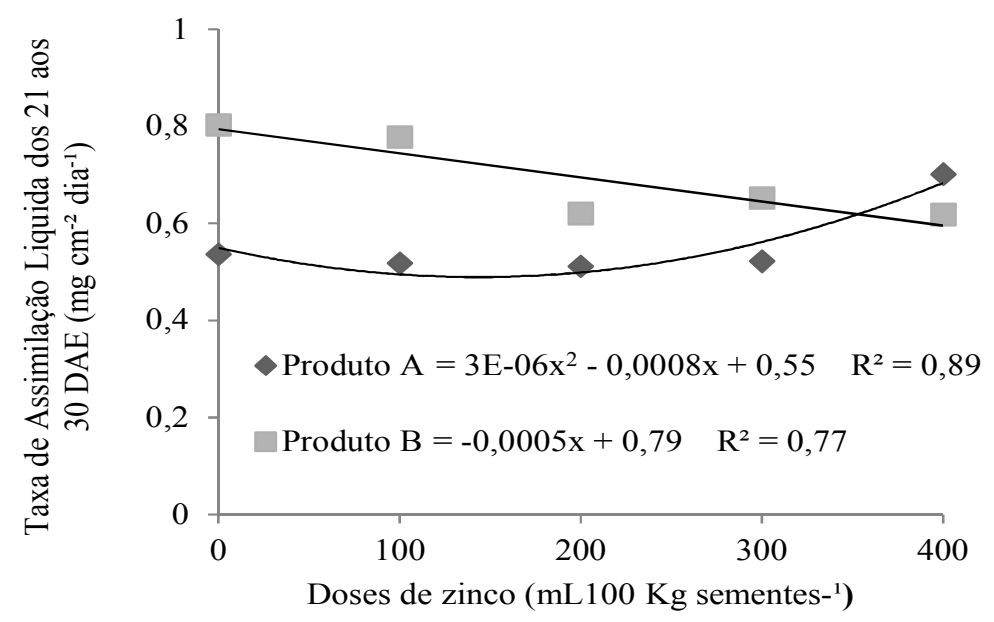

Fonte: Elaboração dos autores.

De modo geral, observa-se que os produtos estudados a base de zinco apresentam comportamentos diferentes, para as variáveis altura de planta, área foliar e taxa de assimilação líquida (Figura 3 e 4). Constata-se que, para as demais variáveis os produtos apresentaram comportamento semelhante em função do aumento das doses.

\section{Conclusões}

Os produtos Teprosyn ${ }^{\mathrm{TM}} \mathrm{Zn}$ e Quimifol seed $78^{\circledR}$ podem ser usados no tratamento de sementes até as doses de 100 e $200 \mathrm{~mL} 100 \mathrm{~kg}^{-1}$ de sementes respectivamente, sem prejudicar a qualidade fisiológica das sementes.

O produto Teprosyn ${ }^{\mathrm{TM}} \mathrm{Zn}$ com $17 \mathrm{~g} \mathrm{~L}^{-1} \mathrm{de}$ nitrogênio e $600 \mathrm{~g} \mathrm{~L}^{-1}$ de zinco, a partir da dose de $200 \mathrm{~mL} 100 \mathrm{~kg}^{-1}$ de sementes, 30 dias após a emergência, apresenta menor crescimento de planta e área foliar, comparativamente a dose de máxima eficiência técnica.

\section{Referências}

BONNECARRÉRE, R. A. G.; LONDERO, F. A. A.; SANTOS, O.; SCHMIDT, D.; PILAU, F. G.; MANFRON, P. A.; DOURADO NETO, D. Resposta de genótipos de arroz irrigado à aplicação de zinco. Revista da Faculdade Zootecnia Veterinária e Agronomia, Uruguaiana, v. 10, n. 1, p. 109-116, 2003.

BRASIL. Ministério da Agricultura, Pecuária e Abastecimento. Regras para análise de sementes. Ministério da Agricultura, Pecuária e Abastecimento. Secretaria de Defesa Agropecuária. Brasília: Mapa/ACS, 2009. $395 \mathrm{p}$.

BRIGGS, G. E.; KIDD, F.; WEST, C. A quantitative analysis of plant growth. Part II. Annals of Applied Biology, Londres, v. 7, n. 2-3, p. 202-223, 1920. 
CAKMAK, I. Effect of micronutrients on seed quality. In: LI, C. L. (Ed.). Plant nutrition for food security, human health and environmental protection. China: Tsinghua University Press, 2005. p. 384-385.

CARVALHO, N. M.; NAKAGAWA, J. Sementes: ciência, tecnologia e produção. 4. ed. Jaboticabal: Funep, 2000.588 p.

COMISSÃO DE QUÍMICA E FERTILIDADE DO SOLO - RS/SC. Manual de adubação e de calagem para os estados do Rio Grande do Sul e de Santa Catarina. 10. ed. Porto Alegre: NRS/SBCS, 2004. 400 p.

FAGERIA, N. K. Níveis adequados e tóxicos de zinco na produção de arroz, feijão, milho, soja e trigo em solo de cerrado. Revista Brasileira de Engenharia Agrícola e Ambiental, Campiña Grande, v. 4, n. 3, p. 390-395, 2000.

FUNGUETO, C. I.; PINTO, J. F.; BAUDET, L.; PESKE, S. T. Desempenho de sementes de arroz irrigado recobertas com zinco. Revista Brasileira de Sementes, Londrina, v. 32, n. 2. p. 117-115. 2010.

FURLANI, A. M. C.; FURLANI, P. R. Resposta de cultivares de milho a zinco em solução nutritiva. Bragantia, Campinas, v. 55, n. 2, p. 365-369, 1996.

FURLANI, A. M. C.; FURLANI, P. R.; MEDA, A. R.; DUARTE, A. P. Eficiência de cultivares de milho na absorção e utilização de zinco. Scientia Agricola, Piracicaba, v. 62, n. 3, p. 264-273, 2005.

GARDNER, F. P.; PEARCE, R. B.; MITCHELL, R. L. Physiology of crop plants. Ames: Iowa State University Press, 1985. $321 \mathrm{p}$.

HUXLEY, P. A. The effects of artificial shading on some growth characteristics of arabica and robusta coffee seedlings. I. The effects of shading on dry weight, leaf area and derived growth data. Journal of Applied Ecology, London, v. 4, n. 2, p. 291-308. 1967.

LONGNECKER, N. E.; ROBSON, A. D. Distribution and transport of zinc. In: ROBSOM, A. D. Zinc in soils and plants. Dordrecht: Kluwer Academic Publishers, 1993. p. 79-91.

MACHADO, A. A.; CONCEIÇÃO, A. R. Sistema de análise estatística para windows. WinStat. Versão 2.0. Pelotas: UFPel, 2003.

MALAVOLTA, E. Manual de nutrição mineral de plantas. São Paulo: Editora Agronômica Ceres, 2006. $638 \mathrm{p}$.

MALAVOLTA, E.; BOARETTO, A. E.; PAULINO, V. T. Micronutrientes: uma visão geral. In: FERREIRA, M. E.; CRUZ, M. C. P. Micronutrientes na agricultura. Piracicaba: POTAFOS, 1991. p. 1-34.
MARCOS FILHO, J. Testes de vigor: importância e utilização. In: KRZYZANOWSKI, F. C.; VIEIRA, R. D.; FRANÇA NETO, J. B. Vigor de sementes: conceitos e teses. Londrina, 1999. cap. 1, p. 1-21.

NAKAGAWA, J. Testes de vigor baseados no desempenho das plântulas. In: KRZYZANOWSK, F. C.; VIEIRA, R. D.; FRANÇA-NETO, J. B. Vigor de sementes: conceitos e testes. Londrina: ABRATES, 1999. cap. 2, p. 9-13.

NUNES, J. C. Tratamento de semente - qualidades e fatores que podem afetar a sua performance em laboratório. São Paulo: Syngenta Proteção de Cultivos, 2005. $16 \mathrm{p}$.

OHSE, S.; MARODIM, V.; SANTOS, O. S.; LOPES, S. J.; MARAFRON, P. A. Germinação e vigor de sementes de sementes de arroz irrigado tratadas com zinco, boro e cobre. Revista da Faculdade Zootecnia, Veterinária e Agronomia, Uruguaiana, v. 7, n. 1, p. 73-79, 2000.

OHSE, S.; RESENDE, B. L. A.; LISIK, D.; OTTO, R. F. Germinação e vigor de sementes de melancia tratadas com zinco. Revista Brasileira de Sementes. Londrina, v. 34, n. 2, p. 282-292, 2012.

ORIOLI JUNIOR, V.; PRADO, R. M.; LEONEL, C. L.; CAZETTA, D. A.; SILVEIRA, C. M.; QUEIROZ, R. J. B.; BASTOS, J. C. H. A. G. Modos de aplicação de zinco na nutrição e na produção de massa seca de plantas de trigo. Revista de la ciencia del suelo y nutrición vegetal, Temuco, v. 8, n. 1, p. 28-36, 2008.

PRADO, R. M.; FRADE JUNIOR, E. F.; MOUTA, E. R.; SÃO JAÕA, A. C. G.; COSTA, R. S. S. Crescimento inicial e estado nutricional do trigo submetido à aplicação de zinco via semente. Revista de la Ciência del Suelo y Nutrición Vegetal, Temuco, v. 7, n. 2, p. 22-31, 2007.

RIBEIRO, N. D.; SANTOS, O. S. Aproveitamento do zinco na semente na nutrição da planta. Ciência Rural, Santa Maria, v. 26, n. 1, p. 159-165, 1996.

ROZANE, D. E.; PRADO, R. M.; ROMUALDO, L. M.; SIMÕES, R. R. Resposta de plântulas de arroz c.v. Soberana à aplicação de zinco via semente. Ciência e Agrotecnologia, Lavras, v. 32, n. 3, p. 847-854, 2008.

SÁ, M. E. Importância da adubação na qualidade de semente. In: SÁ, M. E.; BUZZETI, S. (Ed.). Importância da adubação na qualidade dos produtos agrícolas. São Paulo: Ícone, 1994. p. 65-98.

SANTOS, O. S.; RIBEIRO, N. D. Fontes de zinco aplicadas em sementes de milho, em solução nutritiva. Ciência Rural, Santa Maria, v. 24, n. 1, p. 59-62, 1994. 
STRECK, E. V.; KÄMPF, N.; DALMOLIN, R. S. D.; KLAMT, E.; NASCIMENTO, P. C.; SCHNEIDER, P.; GIASSON, E.; PINTO, L. F. S. Solos do Rio Grande do Sul. 2. ed. Porto Alegre: EMATER/RS-ASCAR, 2008. $222 \mathrm{p}$.

TUNES, L. M.; OLIVO, F.; BADINELLI, P. G.; CANTOS, A.; BARROS, A. C. A. Testes de vigor em sementes de aveia branca. Revista da Faculdade Zootecnia, Veterinária e Agronomia, Uruguaiana, v. 15, n. 2, p. 94-106, 2008.
VELlOSO, C. B. O.; FEDERIZZI, L. C. Delimitação preliminar da cadeia da aveia branca para consumo humano no Brasil. In: REUNIÃO DA COMISSÃO BRASILEIRA DE PESQUISA DE AVEIA, 20., 2000, Pelotas. Anais... Pelotas: Editora e Gráfica Universitária UFPel, 2000. p. 181-183.

YAGI, R.; SIMILI, F. F.; ARAÚJO, J. C.; PRADO, R. M.; SANCHEZ, S. V.; RIBEIRO, C. E. R.; BARRETTO, V. C. M. Aplicação de zinco via sementes e seu efeito na germinação, nutrição e desenvolvimento inicial do sorgo. Pesquisa Agropecuária Brasileira, Brasília, v. 41, n. 4, p. 655-660, 2006. 